Original Research Article

\title{
A study to evaluate the skeletal muscle relaxant property of Pregabalin and Gabapentin in albino rats
}

\author{
Sushma V. Naidu ${ }^{1}$, Vibha Rani ${ }^{2 *}$
}

${ }^{1}$ Department of Pharmacology, Oxford Medical College, Hospital and Research Centre, Bangalore, Karnataka, India ${ }^{2}$ Department of Pharmacology, Malla Reddy Medical College for Women, Hyderabad, Telangana, India

Received: 10 April 2019 Accepted: 07 May 2019

*Correspondence to:

Dr. Vibha Rani,

Email: vibha_udupi@ yahoo.co.in

Copyright: () the author(s), publisher and licensee Medip Academy. This is an openaccess article distributed under the terms of the Creative Commons Attribution NonCommercial License, which permits unrestricted noncommercial use, distribution, and reproduction in any medium, provided the original work is properly cited.

\begin{abstract}
Background: Skeletal muscle relaxants are the drugs which reduce unwanted spasm without interfering with consciousness and voluntary movements. The centrally acting muscle relaxants like Diazepam, is known to be GABA mimetics and other antiepileptics like Gabapentin and Pregabalin also act through the release of GABA. This study is done to investigate skeletal muscle relaxant property of these drugs in comparison to Diazepam.

Methods: T Models used in the experiment are Grip Strength Test, Rota Rod Method, Beam Walk Test, Photoactometer Test. Animals were divided into 6 groups of 6 rats each: Group 1: Control group treated with normal saline $(0.1$ $\mathrm{ml} / 10 \mathrm{gm}$ ), Group 2: Standard-15mg/kg of Diazepam, Group 3:T1-60 mg/kg of Gabapentin, Group 4:T2-10 mg/kg of Pregabalin, Group 5:T3-60 mg/kg of Gabapentin+Diazepam, Group 6:T4- $10 \mathrm{mg} / \mathrm{kg}$ of Pregabalin+Diazepam. Mean and standard deviation was calculated for each group. One way ANOVA was used for multiple group comparisons followed by post hoc Tukey's test for statistical significance between the groups.

Results: Treatment with the above test drugs produced significant muscle relaxation and caused decreased fall off, sliding time, increase climbing time and decreased locomotor activity in all models indicating motor incoordination. The results obtained from both standard and test groups showed a highly significant difference in muscle relaxation when compared with the control group.

Conclusions: The test drugs showed skeletal muscle relaxant property in rats comparable to Diazepam. In view of these results, it can open a new avenue for these drugs to be used as skeletal muscle relaxants after conducting clinical trials.
\end{abstract}

Keywords: Diazepam, Gabapentin, Pregabalin, Skeletal muscle relaxation

\section{INTRODUCTION}

Skeletal muscle relaxants are those drugs which reduce unwanted spasm or spasticity without interfering with consciousness and normal voluntary movements. They find an important application in various neurological or painful musculoskeletal disorders. ${ }^{1}$ The earliest known use of muscle relaxant drugs dates back to the $16^{\text {th }}$ century. By 1943 neuromuscular blocking drugs became established as muscle relaxants in the practice of anesthesia and surgery. ${ }^{2}$ According to the World Health Organization report
(WHO, Geneva;2001) approximately 450 million people suffer from a neurological or behavioral disorder. This amounts to $12.3 \%$ of the global burden of disease and will rise to $15 \%$ by $2020 .^{3}$

Drugs that affect skeletal muscle function are used to alleviate symptoms such as muscle spasms, pain and hyperreflexia. They include two different therapeutic groups: those used during surgical procedures and in the intensive care unit (ICU) to produce muscle paralysis (i.e. neuromuscular blockers) and those used to reduce 
spasticity in a variety of painful conditions (i.e. spasmolytics). Neuromuscular blocking drugs interfere with the transmission at the neuromuscular end plate and lack central nervous system activity. These compounds are used primarily as adjuncts during general anesthesia to facilitate tracheal intubation and optimize surgical conditions while ensuring adequate ventilation. Drugs in the spasmolytic group have traditionally been called "centrally acting" muscle relaxants and are used primarily to treat chronic back pain and painful fibromyalgic conditions. $^{4}$

Antispasticity medications reduce muscle tone by acting either on the central nervous system (CNS) or directly on skeletal muscles. ${ }^{5}$ Agents that work on the CNS are called as centrally acting skeletal muscle relaxants and it includes drugs like Baclofen, Tizanidine, Riluzole and Benzodiazepines (Diazepam), whereas peripheral agents include Dantrolene and Botulinum toxin. Centrally acting skeletal muscle relaxants which are known to be GABA mimetics cause muscular relaxation without loss of consciousness. $^{4}$

Diazepam is useful alone or in combination for relieving spasticity especially in patients with lesions of the spinal cord. Diazepam acts by selectively binding to GABA-A receptor. It enhances the effectiveness of GABA by opening chloride channels. The newer antiepileptics like Gabapentin and Pregabalin which also have great role in the treatment of neuropathic pain also act through release of GABA. $^{6}$ Gabapentin (1-[aminomethyl]cyclohexaneacetic acid; is an anticonvulsant approved in the United States in 1994 for use in adult patients with partial epilepsy also found to be effective in the treatment of pain syndromes, including painful diabetic neuropathy. Gabapentin is structurally related to $\gamma$-aminobutyric acid (GABA), a neurotransmitter that plays a role in the pain transmission and modulation. Gabapentin increases the concentration and probably the rate of synthesis of GABA in the brain, which may enhance non-vesicular GABA release. ${ }^{7}$ Gabapentin has shown considerable promise as a spasmolytic agent in several studies involving patients with multiple sclerosis. ${ }^{8}$ Pregabalin is a novel centrally acting neuromodulating agent that was approved by USFDA for the treatment of painful diabetic peripheral neuropathy and post herpetic neuralgia. It is a newer analog of Gabapentin used as an adjunct in the treatment of partial seizures with or without secondary generalisation. Pregabalin is a structural analogue of, but functionally unrelated to, the naturally occurring transmitter GABA. It is also used in the treatment of epilepsy, generalized anxiety disorder, neuropathic pain and in fibromyalgia., ${ }^{9,10}$ It may also prove useful in relieving painful disorders that involve a muscle spasm component.

Gabapentinoids are anticonvulsant medications that have shown benefit as antispasticity agents in studies involving patients with spinal cord injuries. ${ }^{11-13}$ Both Gabapentin and Pregabalin inhibit the $\alpha_{2} \delta$ subunit of L-type voltage-gated
$\mathrm{Ca}^{2+}$ channels, which are thought to inhibit glutamate release. ${ }^{14}$ Both agents have demonstrated efficacy in treatment of neuropathic pain and spasticity in patients with Multiple Sclerosis. ${ }^{15}$ Gabapentin has been shown to have a dose-related efficacy in controlling spasticity at dosages of $1,200 \mathrm{mg}$ to $3,600 \mathrm{mg} /$ day. ${ }^{11}$

In a retrospective case series that evaluated Pregabalin (75 to $300 \mathrm{mg}$ bid) as a monotherapy for spasticity in 22 patients, 12 patients perceived improvements in spasticity and 8 patients experienced adverse effects that lead to discontinuation. ${ }^{13}$ Overall, the role of gabapentinoids as monotherapy for spasticity remains unclear. They may be beneficial adjuncts in patients who have spasticity and neuropathic pain. Diazepam belonging to benzodiazepine group has got FDA approval for treatment of spasticity and muscle spasms. ${ }^{7}$ Diazepam binds to $\mathrm{GABA}_{\mathrm{A}}$ receptors and potentiates GABAergic activity by increasing chloride conductance, which results in presynaptic inhibition in the spinal cord. ${ }^{5,16}$ Diazepam has demonstrated efficacy in the management of spasticity associated with spinal cord injury, hemiplegia and multiple Sclerosis. However, it is not often recommended as a first-line agent due to risks of sedation and a potential for dependence or abuse.

Gabapentin and Pregabalin are well tolerated and with low adverse effect and drug interaction profile, may offer effective drugs as skeletal muscle relaxants apart from being very effective drugs for neuropathies. The primary purpose of this study was to determine the comparative efficacy of Gabapentin and Pregabalin with Diazepam which also has GABA mimetic activity. Hence it is worthwhile to investigate the skeletal muscle relaxant property of these drugs by evaluating their effects with commonly used antispasticity drugs like Diazepam.

\section{METHODS}

\section{Animals}

A total of 36 Swiss albino rats aged 10-12 weeks of either sex weighing about 150-180 g were obtained from the Central animal house, JSS Medical College, Mysore. The animals were fed with standard pellet diet and water ad libitum and were maintained under standard conditions of temperature, humidity and 12 hour light-dark cycle.

\section{Drugs and chemicals}

Normal saline- $0.9 \% \mathrm{NaCl}$ solution, Diazepam-10 mg/kg, Gabapentin-60mg/kg BW, Pregabalin-10mg/kg BW. All the drugs were administered orally at different doses.

\section{Experimental design}

The Animals were divided into 6 groups of 6 rats each

\section{Group 1}

Control group treated with normal saline $(0.1 \mathrm{ml} / 10 \mathrm{gm})$ 


\section{Group 2}

Standard group treated with $15 \mathrm{mg} / \mathrm{kg}$ of Diazepam

Group 3

T1 treated with $60 \mathrm{mg} / \mathrm{kg}$ of Gabapentin

Group 4

T2 treated with10 mg/kg of Pregabalin

\section{Group 5}

T3 treated with60 mg/kg of Gabapentin+Diazepam

\section{Group 6}

T4 treated with10 mg/kg of Pregabalin+Diazepam

Models of experiment used are Grip Strength Test, Rota Rod Method, Beam Walk Test, Photoactometer Test.

\section{Grip strength test}

This test is performed to access neuromuscular function in rats which will be influenced not only by sedative drugs and skeletal muscle relaxant compounds but also by toxic agents. The animals were proposed to a horizontal thin thread or metallic wire suspended about $10 \mathrm{~cm}$ in the air, which they immediately grasp with their fore limbs. Normal animals are able to catch the wire with fore limbs and climb up with in 5 seconds and the animals that are not able to touch the wire are considered as impaired. Each rat will be tested for grip strength. Parameters observed are the time required to catch the wire with fore limbs and time of fall before and after administration of drugs. ${ }^{17}$

\section{Rota rod method}

This test is used to evaluate the activity of drugs interfering with motor coordination. The application consists of horizontal metal rod of $3 \mathrm{~cm}$ diameter attached to a motor with the speed 20-25 rpm. The rod is divided in five reactions with wooden compartment. It allows simultaneous testing of five rats. The rod is at a height of $50 \mathrm{~cm}$ above the table top in order to discourage the animal from falling off. The test animals along with normal animals are placed on rotating rod and tested for the time of fall from the roller and their behavior before and after administration of corresponding drugs. The difference in fall of time from the rotating rod between the control and treated rats was taken as an index of muscle relaxation. ${ }^{18}$

\section{Photoactometer Test}

It is mainly used to study the locomotor activity. A photoactometer may have square or round area in which the animal moves. Both mice and rat can be used for testing in the apparatus. Most of the CNS-acting drugs influence the locomotor activities in human and animals. The loco motor activity can be easily measured using a photoactometer which operates on photoelectric cell which is connected in a circuit with a connector. To see the locomotor activity, the photoactometer was turned on and each mouse was placed individually in the activity cage for $5 \mathrm{~min}$. The basal activity score for all the animals was noted. When the beam of light falling on the photocell is cut off by the animal, a count is recorded. The total number of cut-offs are measured mechanically for five minutes. The difference in activity before and 60 minutes after drug administration was noted and percentage decrease in motor activity calculated. ${ }^{19}$

\section{Beam walk test}

This test is used to evaluate the activity of the drugs interfering with the motor coordination. In this test, the ability of animals to walk on the beam is evaluated. The apparatus consists of a horizontal metal rod of $1 \mathrm{~cm}$ diameter which is evaporated by two-side stands at $30 \mathrm{~cm}$ height. The animals are kept in the center of the rod to allow walking on the beam. The falling time is noted and the difference between falling time before and after drug administration and compared to the control group. ${ }^{20-22}$

\section{Statistical analysis}

The data obtained was analysed using SPSS version 20 . Mean and standard deviation was calculated for each group. One way ANOVA was used for multiple group comparisons followed by post hoc Tukey's test for statistical significance between groups and $\mathrm{p}$ value $<0.05$ was considered to be statistically significant.

\section{RESULTS}

\section{Grip strength test}

The standard and the test group animals showed significant increase in the time taken to catch the wire with their fore limbs compared to control and also there was significant reduction in the time spent on the wire by holding position compared to control group indicating loss of motor coordination. The standard drug Diazepam showed a highly significant effect $(84 \%)$ when compared to the control ( $p<0.01)$. All the test groups showed increase in muscle relaxation, that is, $40 \%$ (with $\mathrm{T} 1$ ), $37.5 \%$ (with T2), $68 \%$ (with T3) and 76\% (with T4), when compared to the control. Maximum muscle relaxation was observed with T4 group (Table 1).

\section{Rota rod test}

In this test, Pregabalin and Gabapentin and the combination groups showed highly significant reduction in the time spent by the animals on the revolving rod when compared to the control $(p<0.01)$. The standard drug (Diazepam) also showed a highly significant effect 
$(85.2 \%)$ when compared to the control $(p<0.01)$. All the test groups showed increase in muscle relaxation that is, $51.6 \%$ (with T1), $50.7 \%$ (with T2), $58.2 \%$ (with T3) and $57.5 \%$ (with T4) when compared to the control. Maximum muscle relaxation was observed with $\mathrm{T} 4$ group $(10 \mathrm{mg} / \mathrm{kg}$ BW of Pregabalin with Diazepam).
The result from the Rota rod test showed that the drug significantly reduced the motor coordination in the tested animals (Table 2).

Table 1: Effect of the drugs on time of fall in Grip Strength test.

\begin{tabular}{|c|c|c|c|c|}
\hline \multirow{2}{*}{ Groups } & \multicolumn{2}{|c|}{ Time of fall from wire (sec) } & \multirow{2}{*}{$\%$ Change in activity } & \multirow[t]{2}{*}{ P value* } \\
\hline & Before drug & After drug & & \\
\hline Control & $45.33 \pm 8.33$ & $41.5 \pm 8.066$ & $8.5 \%$ & \multirow{6}{*}{$<0.05$} \\
\hline Standard & $42.83 \pm 16.09$ & $7.16 \pm 10.14$ & $84 \%$ & \\
\hline $\mathrm{T} 1$ & $43.66 \pm 11.95$ & $26.33 \pm 9.136$ & $40 \%$ & \\
\hline $\mathrm{T} 2$ & $40.16 \pm 3.05$ & $25.66 \pm 7.67$ & $37.5 \%$ & \\
\hline $\mathrm{T} 3$ & $46.66 \pm 5.00$ & $15.83 \pm 8.98$ & $68 \%$ & \\
\hline $\mathrm{T} 4$ & $47 \pm 6.066$ & $16.66 \pm 9.099$ & $76 \%$ & \\
\hline
\end{tabular}

All values are expressed in Mean \pm Standard deviation, (*Post hoc Tukey's test: $p$ value $<0.05$ is significant).

Table 2: Effect of the drugs on time spent on Rota Rod.

\begin{tabular}{|llll|}
\multirow{2}{*}{ Groups } & \multicolumn{3}{c}{$\begin{array}{c}\text { Time spent on rotating rod in Rota rod apparatus (sec) } \\
\text { p }\end{array}$} \\
\cline { 2 - 4 } & Before drug administration & $\mathbf{3 0}$ min after drug administration & \% Change in activity \\
\hline Control & $218.5+8.066$ & $218+5.95$ & $0.5 \%$ \\
\hline Standard & $212+10.14$ & $31.5+1.47$ & $85.2 \%$ \\
\hline T1 & $229+1.41$ & $113.5+8.5$ & $51.6 \%$ \\
\hline T2 & $216+14.46$ & $106.6+9.01$ & $50.7 \%$ \\
\hline T3 & $221+12.41$ & $92.5+7.296$ & $58.2 \%$ \\
\hline T4 & $216+10.86$ & $92.33+6.368$ & $57.5 \%$ \\
\hline
\end{tabular}

All values are expressed in Mean \pm Standard deviation, (*Post hoc Tukey's test: $p$ value $<0.05$ is significant).

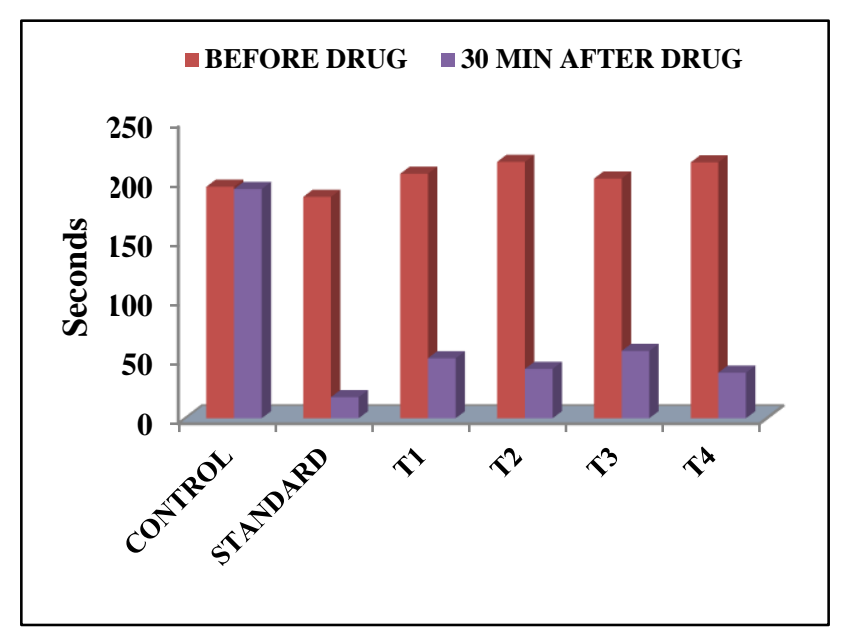

Figure 1: Effect of drugs on Photoactometer test.

\section{Photoactometer test}

The percentage reduction in the locomotor activity with the standard drug (Diazepam) showed that there was highly significant reduction in locomotor activity compared to control $(91.5 \%)$ while the test groups and the combination of test and standard groups also showed significant reduction in locomotor activity compared to control, the percentage reduction being $75.5 \%$ (with T1), $80.72 \%$ (with T2), $71.86 \%$ (with T3) and $82.09 \%$ (with T4), which is comparable to the standard group values. Maximum muscle relaxation was observed with T4 group (10 mg/kg BW of Pregabalin with Diazepam). The values were highly significant $(p<0.005)$ (Figure 1$)$.

\section{Beam walk test}

The standard and test group of animals walked less distance and there was significant reduction in the falling time in both the groups as compared to control group indicating loss of motor coordination .The standard drug (Diazepam) also showed a highly significant effect $(72.79 \%)$ when compared to the control $(p<0.01)$. All the test groups showed increase in muscle relaxation that is, $40.5 \%$ (with T1), $60.11 \%$ (with T2), 39.09\% (with T3) and $55.47 \%$ (with T4) when compared to the control. Maximum muscle relaxation was observed with T2 group (10mg/kg BW of Pregabalin). The result from the beam walk test showed that the drug significantly reduced the motor coordination of the tested animals (Figure 2). 


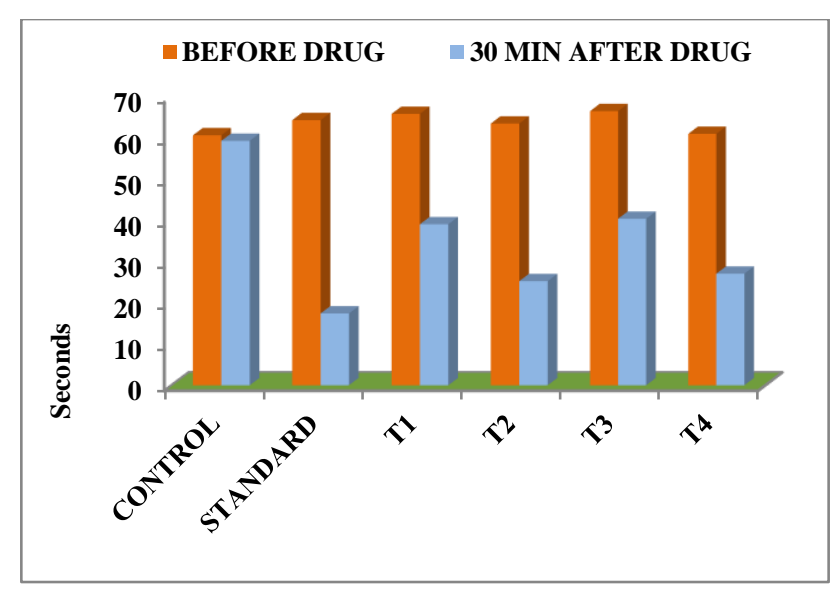

Figure 2: Effect of drugs on time of fall in Beam walk test.

\section{DISCUSSION}

The objective of this study was to investigate the skeletal muscle relaxant activities of the commonly used neuropathic drugs like Pregabalin and Gabapentin.

Gabapentin, a derivative of $\gamma$-aminobutyric acid (GABA), has half-life of 5-7 hrs with good pharmacokinetic profile, it is not metabolized, not bound to plasma proteins and excreted unchanged in the urine. ${ }^{23}$ Also Gabapentin is found to produce mild side effects in humans. ${ }^{24}$ In addition it also has favorable safety profile, does not interfere with hepatic enzymes with less drug interactions. ${ }^{25}$ Pregabalin a successor of Gabapentin has highly predictable and linear pharmacokinetics, does not bind to plasma proteins and does not induce or inhibit liver enzymes. It is one few antiepileptic drugs with minimum drug interactions. ${ }^{26}$ The other major advantages of Pregabalin includes it is very easy to use, relative reliability. ${ }^{27}$ Accordingly, Gabapentin and Pregabalin was selected as test drug in this comparative study because of its excellent pharmacokinetic features which are already established and also these two test drugs and the standard drug Diazepam also act via GABA receptors, it was considered worthwhile to evaluate the potential of these newer drugs which are finding great promise in the treatment of epilepsy and neuropathic pain.

In this study, maximum muscle relaxation was seen in T4 group in Grip strength test where the rats showed increased time to hold the wire with decreased time spent on it indicating motor incoordination. In Rota rod test, there was reduction in the time spent by the rats on the revolving rod, and this was found to be greatest with the T4 group. In Photoactometer test, maximum muscle relaxation was observed withT4 group indicating reduction in locomotor activity. The rats walked less distance with significant reduction in the falling time in the Beam walk test and the maximum muscle relaxation in this model was observed with T2 group. The results obtained was subjected to hoc Tukey's test showed highly significant difference in muscle relaxation between the standard and test groups compared with the control group. This is an innovative research study in which Gabapentin and Pregabalin are compared with Diazepam for their skeletal muscle action and as such there are no previous studies done on the same. So this new indication of use of the drugs as skeletal muscle relaxant, opens scope for future clinical studies in this field which will further strengthen the findings of our study.

\section{CONCLUSION}

In this study, the test drugs-Pregabalin and Gabapentin, showed skeletal muscle relaxant property in rats comparable to Diazepam. Their induction showed muscle weakness, muscle incoordination, loss of loco motor activity. In view of these results, it can open a new prospect for these drugs to be used as skeletal muscle relaxants after conducting clinical trials. Also administration of skeletal muscle relaxants in situations like general anaesthesia to patients who are on long term treatment with GABA mimetics like Pregabalin and Gabapentin should be done cautiously as they have shown adjuvant effect along with commonly used muscle relaxants.

\section{ACKNOWLEDGEMENTS}

Authors would like to acknowledge institution JSS Medical College, Mysore for giving authors an excellent opportunity to conduct this study.

Funding: No funding sources

Conflict of interest: None declared

Ethical approval: The study was approved by the Institutional Ethics Committee

\section{REFERENCES}

1. Satoskar RS, Rege NN, Tripathi RK, Bhandarkar SD. Skeletal muscle relaxants, Pharmacology and pharmacotherapeutics. $25^{\text {th }}$ Ed. RELX India Pvt Ltd. Popular Prakashan;2017:317-325.

2. Veena NS, Sivaji K, Benerji GV, Babu MF, Kumari DR. Skeletal muscle relaxant property of diazepam by using rotarod on albino mice. Indian J Basic Applied Med Res. 2015;4(4):714-21.

3. George M, Joseph L, Sharma A. Antidepressant and skeletal muscle relaxant effects of the aqueous extract of the Prosopis cineraria. Brazilian J Pharmaceut Sci. 2012 Sep;48(3):577-81.

4. Seth SD, Seth Vimlesh. Skeletal muscle relaxants, Textbook of pharmacology. $3^{\text {rd }}$ Ed. Delhi, India:Elsevier-New;2009:36-38.

5. Katzung BG, Trevor AJ. Skeletal muscle relaxants, Basic \& Clinical Pharmacology. 13 ${ }^{\text {th }}$ Ed. New York, NY: McGraw-Hill; 2015:267-283.

6. Rowbotham M, Harden N, Stacey B, Bernstein P, Magnus-Miller L. Gabapentin for the treatment of postherpetic neuralgia: a randomized controlled trial. JAMA. 1998 Dec 2;280(21):1837-42. 
7. Morello CM, Leckband SG, Stoner CP, Moorhouse DF, Sahagian GA. Randomized double-blind study comparing the efficacy of gabapentin with amitriptyline on diabetic peripheral neuropathy pain. Arch Intern Med. 1999 Sep 13;159(16):1931-7.

8. Backonja M, Beydoun A, Edwards KR, Schwartz SL, Fonseca V, Hes $\mathrm{M}$, et al. Gabapentin for the symptomatic treatment of painful neuropathy in patients with diabetes mellitus: a randomized controlled trial. JAMA. 1998 Dec 2;280(21):1831-6.

9. Elinor Ben-Menachem. Pregabalin Pharmacology and Its Relevance to Clinical Practice. Epilepsia 2004;45(6):13-8.

10. Crofford LJ, Rowbotham MC, Mease PJ, Russell IJ, Dworkin RH, Corbin AE, et al. Pregabalin for the treatment of fibromyalgia syndrome: results of a randomized, double-blind, placebo-controlled trial. Arthritis Rheum. 2005 Apr;52(4):1264-73.

11. Priebe MM, Sherwood AM, Graves DE, Mueller M, Olson WH. Effectiveness of gabapentin in controlling spasticity: a quantitative study. Spinal Cord. 1997 Mar;35(3):171.

12. Gruenthal M, Mueller M, Olson WL, Priebe MM, Sherwood AM, Olson WH. Gabapentin for the treatment of spasticity in patients with spinal cord injury. Spinal Cord. 1997;35(10):686-9.

13. Bradley LJ, Kirker SG. Pregabalin in the treatment of spasticity: a retrospective case series. Disabil Rehabil. 2008;30(16):1230-2.

14. Mueller ME, Gruenthal M, Olson WL. Gabapentin for relief of upper motor neuron symptoms in multiple sclerosis. Arch Phys Med Rehabil. 1997;78(5):521-4.

15. Pollmann W, Feneberg W. Current management of pain associated with multiple sclerosis. CNS Drugs. 2008;22(4):291-324.

16. Greenfield LJ. Molecular Mechanisms of Antiseizure Drug Activity at GABA-A Receptors. Seizure. 2013;22(8):589-600.

17. Nevins ME, Nash SA, Beardsley PM. Quantitative grip strength assessment as a means of evaluating muscle relaxation in mice. Psychopharmacology (Berl). 1993;110(1-2):92-6.

18. Hamm RJ, Pike BR, O'Dell DM, Lyeth BG, Jenkins LW. The rota rod test: an evaluation of its effectiveness in assessing motor deficits following traumatic brain injury. J neurotrauma. 1994;11(2):187-96.

19. Al-Naggar TB, Gomez-Serranillos MP, Carretero ME, Villar AM. Neuropharmacological activity of Nigella sativa L. extracts. J ethnopharmacol. 2003 Sep 1;88(1):63-8.

20. Luong TN, Carlisle HJ, Southwell A, Patterson PH. Assessment of Motor Balance and Coordination in Mice using the Balance Beam. J Vis Exp. 2011;(49):2376.

21. Sousa N, Almeida OF, Wotjak CT. A hitchhiker's guide to behavioral analysis in laboratory rodents. Genes Brain Behav. 2006;5 Suppl 2:05-24.

22. Zhang X, Li H, Hu S, Zhang L, Liu C, Zhu C, et al. Brain edema after intracerebral hemorrhage in rats: the role of inflammation. Neurol India. 2006 Oct 1;54(4):402.

23. Aryal B, Tae-Hyun K, Yoon-Gyoon K, Hyung-Gun K. A comparative study of the pharmacokinetics of traditional and automated dosing/blood sampling systems using gabapentin. Indian J Pharmacol. 2011 May;43(3):262.

24. Baillie JK, Power I. The mechanism of action of gabapentin in neuropathic pain. Current opinion in investigational drugs (London, England: 2000). 2006 Jan;7(1):33-39.

25. Kukkar A, Bali A, Singh N, Jaggi AS. Implications and mechanism of action of gabapentin in neuropathic pain. Arch Pharm Res. 2013 Mar;36(3):237-51.

26. Ben-Menachem E. Pregabalin pharmacology and its relevance to clinical practice. Epilepsia. 2004;45 Suppl 6:13-8.

27. Freynhagen R, Strojek K, Griesing T, Whalen E, Balkenohl M. Efficacy of pregabalin in neuropathic pain evaluated in a 12-week, randomised, doubleblind, multicentre, placebo-controlled trial of flexibleand fixed-dose regimens. Pain. 2005 Jun;115(3):25463.

Cite this article as: Naidu SV, Rani V. A study to evaluate the skeletal muscle relaxant property of Pregabalin and Gabapentin in albino rats. Int $\mathrm{J}$ Basic Clin Pharmacol 2019;8:1381-6. 